\title{
Research on Vocational Training Countermeasures of New Generation Migrant Workers
}

\author{
Qinglan Luo ${ }^{1, a}$, Xinze Li ${ }^{1, b}$ and Chunyan Wang ${ }^{1, \mathrm{C}^{*}}$ \\ ${ }^{1}$ College of Business Administration, Jilin Engineering Normal University, Changchun, China \\ a sunny203@126.com, b 947402524@qq.com, ${ }^{c}$ 541012329@qq.com
}

Keywords: New generation migrant workers; Investigation; Vocational training; Countermeasures

\begin{abstract}
The public pay more attention to the vocational training of migrant workers. And employment of the new generation migrant workers is the key problems received more and more attention now. We conducted a survey about the vocational training needs of the new generation migrant workers in some cities and regions. Through the questionnaire we point out the existing problems in the vocational training of the new generation migrant workers, and put forward the effective countermeasures to speed up the vocational training process of the new generation migrant workers from four aspects, which are the government, enterprises, vocational training institutions, migrant workers.
\end{abstract}

\section{Introduction}

The migrant workers made significant contribution to the economic development in China. They are the important driving force to realize the industrialization, urbanization and modernization, and received the social attention for long time. The first generation migrant workers gradually withdrew from the historical stage after 30 years since reform and opening. The generation migrant workers of 80 s and 90s become the main body in the society who were called the new generation migrant workers [1]. With the growing number of the new generation migrant workers, employment and urban development faced more pressure and challenges in China. As an important way to human capital investment, the vocational training is beneficial to improve the professional skills and comprehensive quality of the new generation migrant workers [2]. And it also helps to increase the stability of employment and establish the troops of the high-quality industrial workers. Report of the 18th national congress of the CPC clearly puts forward to carry out the large-scale vocational training, especially cultivate hundreds of millions migrant workers into the skilled workers [3].So research on the vocational training of the new generation migrant workers is useful for solving the new generation of migrant workers employment.

\section{Investigation Subjects and Data Sources}

In order to better understand the vocational training needs and trouble of the new generation migrant workers, we conduct a survey about the vocational training needs and will of the $t$ the new generation migrant workers within Jilin province. 300 questionnaires are given out and recycling effective questionnaire 266, effective questionnaire recovery rate $88.7 \%$. Distributed objects are the new generation migrant workers of 80 s and 90s. Main survey area are Changchun, Jilin, Songyuan, Baishan, Tonghua etc. which labor input are relatively large cities in Jilin province. To make up for inadequate number of questionnaires, we interview with the six new generation migrant workers in Changchun and know their vocational ability. The basic information of the interviewees is shown in table 1 . 
Table 1 Basic information of interviewees

\begin{tabular}{|c|c|c|c|c|c|}
\hline Name & Sex & Age & $\begin{array}{c}\text { Industry \& } \\
\text { Location }\end{array}$ & $\begin{array}{l}\text { Marital } \\
\text { status }\end{array}$ & Education level \\
\hline A & male & 19 & $\begin{array}{l}\text { Construction, } \\
\text { Changchun }\end{array}$ & No & $\begin{array}{l}\text { Junior high school } \\
\text { drop-outs }\end{array}$ \\
\hline $\mathrm{B}$ & male & 22 & $\begin{array}{l}\text { Transportation, } \\
\text { Changchun }\end{array}$ & Yes & $\begin{array}{l}\text { graduate from } \\
\text { primary school }\end{array}$ \\
\hline $\mathrm{C}$ & female & 20 & $\begin{array}{c}\text { Service, } \\
\text { Changchun }\end{array}$ & No & $\begin{array}{l}\text { Higher vocational } \\
\text { graduation }\end{array}$ \\
\hline $\mathrm{D}$ & female & 25 & $\begin{array}{c}\text { Service, } \\
\text { Jilin }\end{array}$ & Yes & $\begin{array}{c}\text { graduate from } \\
\text { senior high school }\end{array}$ \\
\hline $\mathrm{E}$ & female & 21 & $\begin{array}{l}\text { Telecommunications, } \\
\text { Jilin }\end{array}$ & No & $\begin{array}{l}\text { graduate from } \\
\text { junior college }\end{array}$ \\
\hline $\mathrm{F}$ & male & 28 & $\begin{array}{c}\text { Manufacturing, } \\
\text { Jilin }\end{array}$ & No & $\begin{array}{c}\text { graduate from } \\
\text { senior high school }\end{array}$ \\
\hline
\end{tabular}

\section{Vocational Training Needs of New Generation Migrant Workers}

Vocational Training Motivation. With the comprehensive popularization of nine-year compulsory education and anti-illiteracy campaign, the new generation migrant workers most graduated from the junior high school education level or above. With the improvement of education level and degree, the adaptability and viability of the new generation migrant workers were higher than the old generation of migrant workers in the city [4]. The survey shows that there are 74.4 percent new generation migrant workers are willing to participate in the vocational training which means most of them have strong vocational training needs. They are shown in table 2.

Table 2 Vocational training willing of interviewees

\begin{tabular}{c|c|c}
\hline Training willing & Yes & No \\
\hline Number & 198 & 68 \\
\hline Percentage & $74.4 \%$ & $25.6 \%$ \\
\hline
\end{tabular}

Vocational Training Contents. The survey shows there are 33.5 percent new generation migrant workers hope to receive the skills training, 26.7 percent hope to participant in entrepreneurship training, and 17.7 percent wish to get knowledge of city life. Other new generation migrant workers also want to increase their educational degree, acquire the labor law and other legal knowledge, humanities knowledge, etiquette training, occupational safety and health knowledge and so on. They are shown in fig. 1.

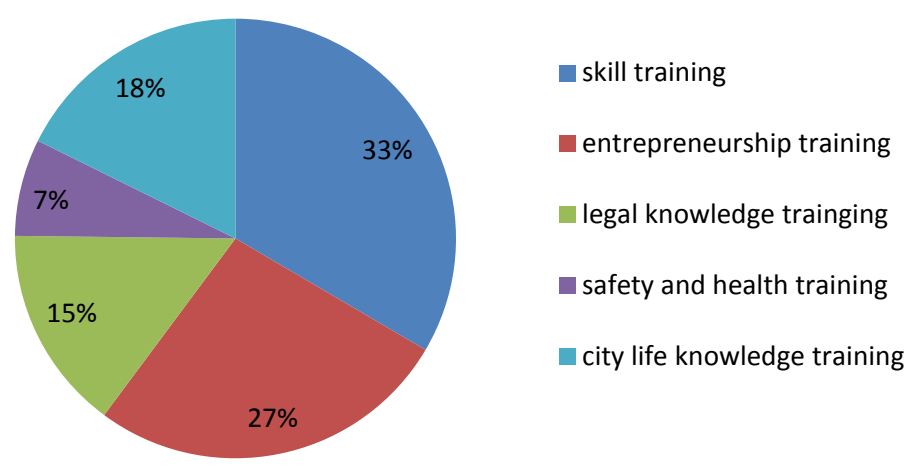

Figure 1. Vocational training contents of new generation migrant workers 
Vocational Training Method. Most new generation migrant workers desired the vocational training methods which are on-the-job training and short-term training. 51.9 percent new generation migrant workers like on-the-job training, 35 percent desire the short-term training and 13.2 percent new generation migrant workers use spare time studying, which shown in fig. 2.

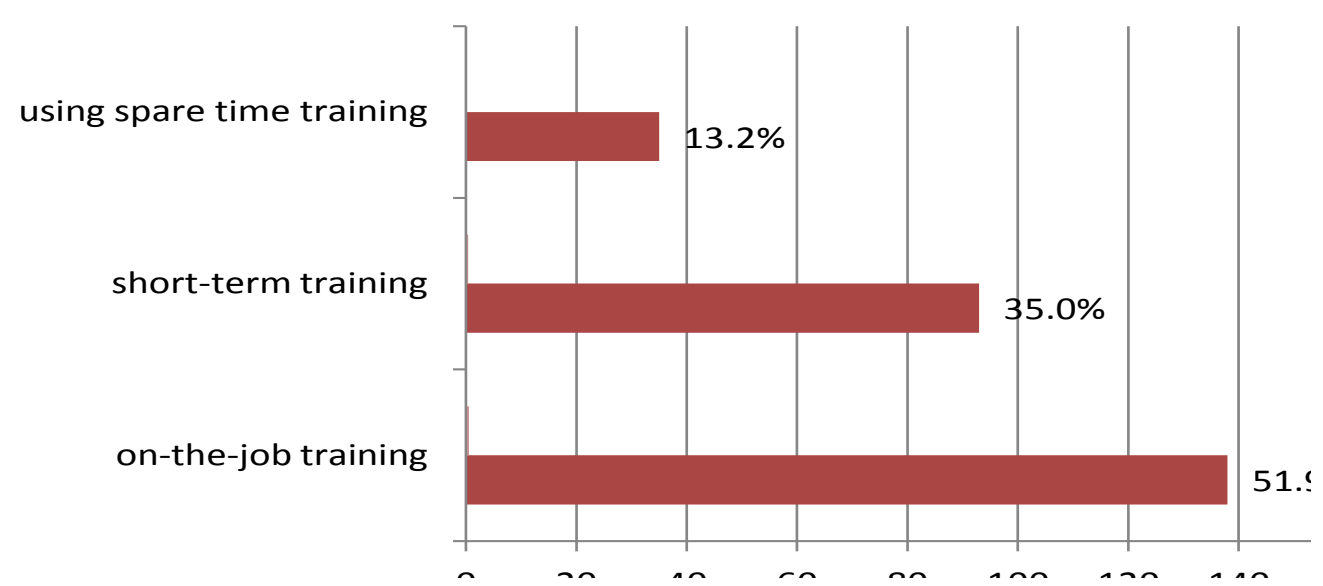

Figure 2. Vocational training method of new generation migrant workers

Vocational Training Form. In the era of Internet the new generation migrant workers like the network training because it save the time and cost, and it is very convenient [5]. The survey showed that 35.7 percent new generation migrant workers like online learning, and 32 percent prefer online and offline combined each other. Both online and offline training form are welcomed by the new generation migrant workers, as shown in fig. 3.

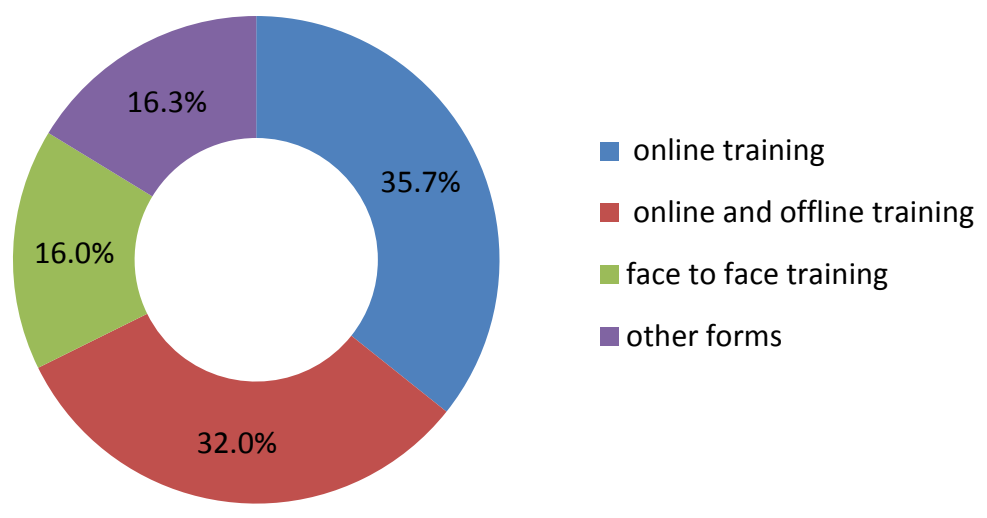

Figure 3. Vocational training form of new generation migrant workers

\section{Vocational Training Dilemma of New Generation Migrant Workers}

Government. The new generation migrant workers access to vocational training information are very narrow, mostly rely on the introduction of friends and relatives. The government's vocational training information is not really spread in place. While the government implements the occupation training programs, it clearly emphasis grant directly paid to the new generation migrant workers who participate in the vocational training [6]. In fact the relevant governmental departments have not really investigated the vocational training needs which led to the training funds use improperly. Training staff did not really improve vocational skill through training. 
Enterprise. Some enterprises only focus on immediate interests, and ignore the long-term economic benefits for enterprise's development brought by vocational training [7]. They were not aware of the importance of vocational training for the future development of enterprises. As we all know the new generation migrant workers have strong mobility, so the enterprises do not willing to undertake training risk. They spent lots of money but failed to achieve the expected effect, unable to retain talent and increase the burden on enterprises. As a result, some organizations invest little training fee to reduce training risk.

Training Institution. Vocational training institutions tend to site the location near the crowd in order to attract more students. The new generation migrant workers distribute unevenly, training institutions in remote areas with few or no distribution location, affecting the training quality of the new generation migrant workers. Most of the training institutions reduce the cost to obtain high benefits in order to get government subsidies [8]. Training institutions do not really investigate the new generation migrant workers training needs. Most of the teachers in the vocational training institutions are mainly external employment. All of these have the great influence on the progress and integrity of the vocational training process.

Individual. The new generation migrant workers lack correct understanding of vocational training. They think that the income and input ratio of vocational training is low. More of them voluntarily participate in the free training or the short-term training that bring benefits for them. The new generation migrant workers doubt the returns obtained by long-term training [9]. They lack of strong independent training and investment consciousness. In addition, the new generation migrant workers consider some factors have effect on their vocational training, which are economic condition, time and place, pattern of training, interests and hobbies and work requirement, each accounted for $87.7 \%, 54.5 \%, 63.2 \%, 33.3 \%$ and $75.4 \%$, as shown in fig .4.

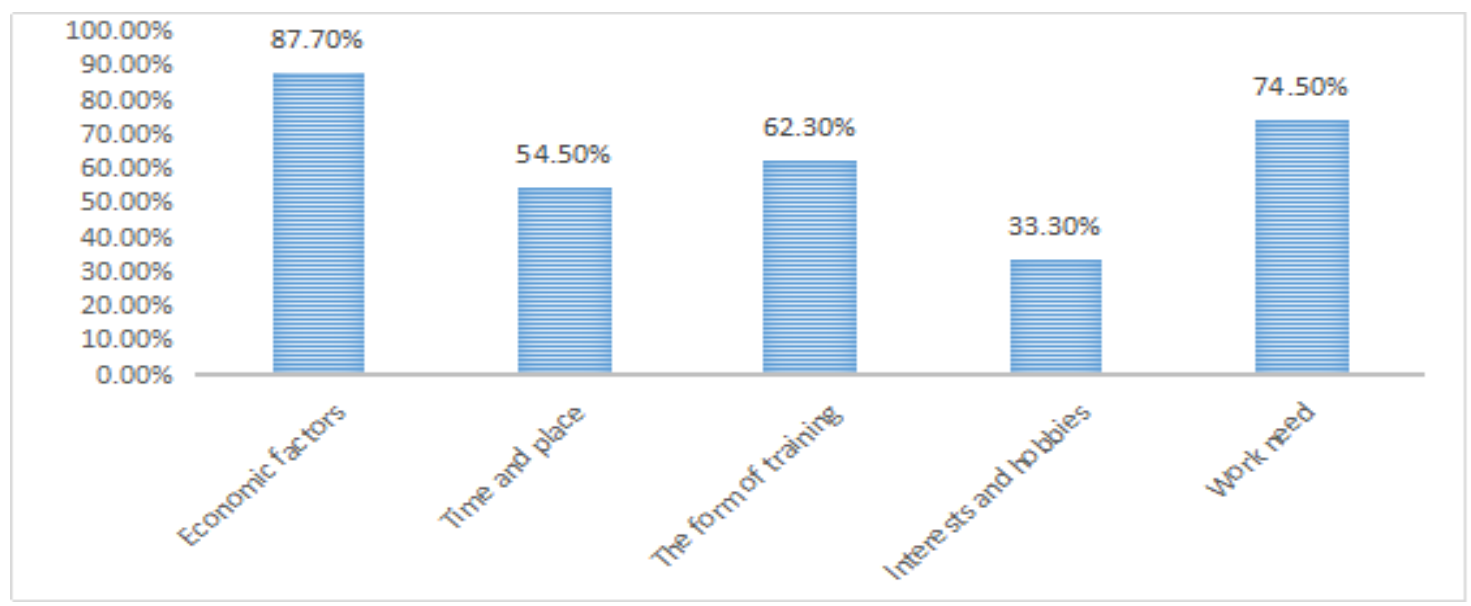

Figure 4. Vocational training influencing factors of new generation migrant workers

\section{Vocational Training Countermeasures of New Generation Migrant Workers}

Government. The government adopt the new communication channels, such as the formal official website, Wechat official accounts, official micro-blog, television and newspapers etc.. These communication forms help the new generation of migrant workers to understand the relevant employment information. Using financial subsidies and establishing financing channels to encourage enterprises, training institutions and the new generation migrant workers actively participant in the vocational training. The government ensures and supervises subsidy policy implementation in place. At the same time the charitable organizations are encouraged to raise funds for the vocational training of the new generation migrant workers.

Enterprise. The new generation of migrant workers is an important employment force for the long-term development of enterprises. With the continuous development of enterprises, they would need more skilled workers in the future. And training is the main form of training talents. 
Enterprises should take sustainable development goal, establish the long-term plan and take the charge of vocational training for the new generation migrant workers. The enterprises continuously improve the quality and adopt various forms of vocational training to attract and retain excellent the new generation migrant workers.

Training institution. The vocational training institutions should increase investment, improve publicity, increase cognition of the new generation migrant workers [10]. It should equip with professional teachers, strict teacher admittance threshold and open the fees to the new generation of migrant workers. According to the vocational training needs of the new generation migrant workers, the vocational training institutions should set up diversified training courses, design enrich and scientific training contents and forms so as to improve the vocational training quality for the new generation migrant workers.

Individual. The new generation migrant workers should establish lifelong learning idea, fully understand their own strengths and weaknesses and establish occupational target. They should also focus on the vocational training policies, arrange personal time to ensure training attendance, improve training efficiency and increase the training investment. The new generation migrant workers constantly update vocational knowledge and skills to obtain long-term development.

\section{Conclusion and Prospect}

The main conclusions of this paper are what the government increase the support of the vocational training of the new generation migrant workers. The enterprises establish long-term development concept to carry out various vocational training activities. Training institutions improve specialty and diversification of the vocational training. Lastly the new generation migrant workers set up the long-term career planning add the vocational training investment and actively participate in the vocational training.

Vocational training is an important way to develop human resources, improve the quality of workers and promote employment. Vocational training can promote the quality of the new generation migrant workers. It has important significance on the regional industrial structure upgrading and the construction of the new rural.

\section{Acknowledgment}

The authors gratefully acknowledge the support of Jilin Provincial Educational Science Planning Office (the project title is "Research on Vocational Training Countermeasures of New Generation Migrant Workers in Jilin Province"; Contract NO. GH16386).

\section{References}

[1] C.J. Liu: Population Research, Vol. 34 (2010) No.2, p.34-39+55-56.

[2] J. Zhang and B.Z. Zhao: Contemporary Vocational Education, Vol. 2 (2011) No.2, p.82-86.

[3] Information on http://cpc.people.com.cn/n/2012/1118/c64094-19612151-1.html.

[4] Z. Zhu, J.Q. Yan and J.F. Jia: Journal of Northeastern University (Social Science), Vol. 19 (2017) No.4, p.371-377.

[5] H.S. Zhan: Education and Vocation, Vol. 49 (2015) No.15, p.8-12.

[6] S.Q. Tian and D.Q. Wang: Research in Educational Development, Vol. 34 (2014) No.19, p.20-25.

[7] W. Xu: A Study on the Vocational Training of New Generation Migrant Workers (Ph.D., Wuhan University, China 2014), p. 24.

[8] X.F. Wang and L. Yu: Adult Education, Vol. 36 (2016) No.11, p.1-4.

[9] P.Y. Chen: Vocational \& Technical Education Forum, Vol. 20 (2013) No.21, p.60-64.

[10]X.Y. Ma, C.X. Chen and H. Lv: Chinese Vocational and Technical Education, Vol. 23 (2015) No.24, p.47-50. 